\title{
Statyba
}

\section{ACOUSTIC CHARACTERISTICS OF PULSED SOUND SOURCES OF VARIOUS TYPES}

\section{Stauskis \& V. Kunigèlis}

To cite this article: V. Stauskis \& V. Kunigèlis (1998) ACOUSTIC CHARACTERISTICS OF PULSED SOUND SOURCES OF VARIOUS TYPES, Statyba, 4:4, 311-315, DOI: 10.1080/13921525.1998.10531423

To link to this article: https://doi.org/10.1080/13921525.1998.10531423

曲 Published online: 26 Jul 2012.

6 Submit your article to this journal $\pi$

Џ Article views: 85 


\title{
IৃVAIRIŲ TIPŲ IMPULSINIŲ GARSO ŠALTINIŲ AKUSTINĖS CHARAKTERISTIKOS
}

\author{
V. Stauskis, V. Kunigèlis
}

\section{1. İvadas}

Apskaičiuojant įvairios paskirties salių akustiką projektavimo stadijoje neįvertinami tokie svarbüs faktoriai, kaip salès forma, garsą absorbuojančių medžiagu išdèstymo vietos, antros ir didesnès eilès atspindžiu struktūros, klausytojo padètis šaltinio atžvilgiu, garso bangu difrakcijos ir interferencijos reiškiniai ir kt. Todèl, norint îvertinti jau pastatytos salès akustines savybes, būtini objektyvių akustinių rodiklių matavimai. Jų reikšmè yra dar didesné, kai salè yra rekonstruojama.

Vienam iš pagrindinių objektyvių akustinių rodiklių - reverberacijos laikui matuoti garso šaltiniu ilgą laiką buvo baltasis triukšmas, perdavimo arba prièmimo trakte naudojant oktavos arba $1 / 3$ oktavos filtrą. Tačiau tiriant pagal tokią sistemą negalime analizuoti garso atspindžiu struktūros. Ši struktūra lemia salès akustines savybes ir formuoja subjektyvius salès akustikos vertinimo kriterijus.

Geriausiai salès akustines savybes nusako trumpas impulsas, kuris naudojamas garso laukui sužadinti. Ji naudojant galime išmatuoti ne tik salès reverberacijos laiką, bet ir ištirti garso atspindžiu struktūrą ir apskaičiuoti ivvairius subjektyvius rodiklius. Tačiau akustiniam impulsui yra keliami ir griežti reikalavimai, kurie matuojant turi būti išlaikyti.

Šio darbo tikslas - tyrimais nustatyti ivairių impulsinių garso šaltinių akustines charakteristikas ir įvertinti, koks impulsas akustiniu požiūriu yra geriausias.

\section{Reikalavimai impulsiniam garso šaltiniui}

Garso šaltinio problema egzistuoja nuo tada, kai buvo atliekami salių akustiniai tyrimai. Parinkti šaltini yra svarbu todèl, kad nuo jo priklauso akustiniu matavimų rezultatai. Impulsinių garso šaltinių pasirinkimas nèra didelis. Jau daug metų tam naudojamas medžioklinis šautuvas arba startinis pistoletas. Jų sukeliami sprogimo tipo impulsai yra plačiai naudojami salių akustikos tyrimams. Naudojant juos pasau- lyje buvo ištirta daug žinomų ịvairios paskirties salių.

M. Barronas [1] kaip garso šaltinị panaudojo pistoletą tirdamas 1230 vietu ir $14000 \mathrm{~m}^{3}$ koncertinès salès ankstyvają reverberaciją, ankstyvosios ir vèlyvosios energiju santykius ir kitus akustinius parametrus. L. Cremeris [2] naudojo 9-to kalibro pistoletą tirdamas 2200 vietu Madrido koncertinès salès akustines savybes. J. Bradley [3-6] kaip garso šaltinị naudojo galingą 38 kalibro pistoletą, kuris išspinduliuodavo pakankamą energijos kieki tiek esant žemiesiems, tiek aukštiesiems dažniams. Taip jis ištyrè didelių salių, kurių tūris siekè nuo 4600 iki $9400 \mathrm{~m}^{3}$, o klausytojų buvo nuo 967 iki 2262, akustiką. B. Rasmussenas ir kt., [7] tirdami dviejų mažu studiju reverberacijos laikus ir kitus parametrus, taip pat naudojo pistoletą ir "Briuel \& Kjaer" firmos šaltini No 4224. L Makrinenko ir kiti [8] startini pistoletą naudojo tirdami akustines savybes tokių žinomų koncertinių salių, kaip Maskvos Sajungos namų Kolonų salè, Konservatorijos Didžioji salè ir kt. Tačiau šiuose darbuose pasigendama informacijos apie ìvairiu sprogimo tipo impulsu akustines charakteristikas ir apie tai, koki impulsą naudojant gaunami geriausi akustiniai rezultatai. Svarbu žinoti, ar šie rezultatai priklauso nuo garso šaltinio.

Impulsas suteikia labai daug informacijos apie patalpos akustines savybes. Jis apima visus muzikinius instrumentus, visus galimus garso signalus, kuriuos sukuria muzikiniai instrumentai, solistai ir aktoriai. Tai yra todèl, kad bet kuri garsinị signalą galime nagrinèti kaip impulsų pasikartojimą. Pasikartojimo dažnį lemia salès geometrija, o kiekvienas muzikinio kūrinio intervalas gali būti išskaidytas ị impulsus.

Kiekvienas impulsas turi savajj spektrą. Galima nustatyti, ar kinta impulso spektras atskirose patalpos zonose arba patalpoje apskritai. Kraakas [9], Reichartas [10] nustaté, kad matuojant reikia naudoti impulsus, kuriu spektro plotis yra ne mažesnis kaip dvi-trys oktavos, tam, kad matavimu rezultatai nepriklausytų nuo interferencinių reiškinių, nedaug keičiantis šaltinio ir mikrofono padetims. 
Sužadinant garso lauką patalpoje dažniausiai naudojami plačiajuosčiai sprogimo pobūdžio impulsai. Naudojant plačiajuosčius ir trumpus impulsus galima gauti gerą atspindžių pasiskirstymą laike ir pasiekti, kad interferencinių reiškinių ịtaka būty kuo mažesnè. Tačiau esant plačiajuosčiams impulsams sunku atlikti atspindžių struktūros dažninę analizę, nes atspindžių struktūra yra iškraipoma pereinamujų fizinio filtro procesų. Kuo didesnè impulso trukmè, tuo jis turi siauresnị juostos plotị.

Kuo daugiau energijos norime sukoncentruoti tam tikru laiko momentu, tuo labiau plačiajuostis dažniụ srityje turi būti signalas. Ir atvirkščiai: kuo daugiau energijos turi būti sukoncentruota tam tikroje dažniụ juostoje, tuo labiau ištęstas laike turi būti signalas. Jeigu reikia sukurti plačiajuostị sužadinimo signalą, pvz., sužadinti visus diapazono dažnius, tai sužadinantis signalas turi būti trumpas impulsas. Šiuo atveju energija, kurią galima suteikti sistemai, yra ribota todèl, kad maksimali garso slègio amplitudè negali viršyti kai kurios ribos.

Jeigu impulsinio signalo $u(t)$ spektras $F($ w) turi būti pakankamai siaurajuostis [11], tai efektyvus normuotas spektro plotis gali būti aprašomas tokia formule:

$$
\Delta e_{f}=\frac{1}{2 \pi|F(\omega)|_{\max }^{2}} \int_{0}^{\infty}|F(\omega)|^{2} d \omega,
$$

čia $\omega$ - kampinis dažnis, ir šis spektro plotis neturi viršyti $1 / 3$ oktavos.

Tačiau sprogimo pobūdžio impulsas šios sąlygos jau yra neatitinka. Be to, impulsinių matavimu rezultatai neturi būti iškraipomi interferencinių efektų, t.y. tiesioginis garsas ir atspindžiai turi sumuotis energetiškai. Toks energetinis tiesioginio ir atsispindẻjusio garso sumavimas yra galimas tada, kai autokoreliaciné funkcija $B(t)=0$ :

$$
B(\tau)=\int_{-\infty}^{\infty} u(t) u(t-\tau) d t=0
$$

Jeigu bus naudojamasi koherentiškumo intervalo sąvoka, kurią aprašo formule

$$
\tau_{k}=\int_{0}^{\infty}\left|\frac{B(\tau)}{B(0)}\right| d \tau
$$

tai pasirodys, kad kuo yra mažesnè impuso trukmè, tuo mažiau interferuos impulsinis signalas.

Impulsinio signalo trukmè turi būti tokios trukmés tam, kad atskiri atspindžiai impulso atsake nesusilietų tarp savęs.

\section{3. İvairių impulsinių garso šaltinių sukuriama atspindžių struktūra}

Šaltinio išspinduliuojamo impuso trukmè turi būti tokia, kad atskiri atspindžiai impulsinèje atspindžiu struktūroje nebūtų susilieję. Tyrimams buvo pasirinkti keturiu tipu sprogimo tipo impulsai - 9-to kalibro garsinis pistoletas, startinis ir žaislinis pistoletai ir 16to kalibro medžioklinis šautuvas. 1 paveiksle pavaizduotas atspindžių pasiskirstymas per pirmąsias $20 \mathrm{~ms}$ sužadinant garso lauką minètais šaltiniais. Tyrimai atlikti $12 \mathrm{~m}^{2}$ kambaryje. Mikrofono atstumas nuo impulsinio garso šaltinio visais atvejais buvo $1 \mathrm{~m}$.

Nagrinėdami salès atsaką ì skirtingus sužadinimo impulsus matome daug atspindžių, kurie pasiekia klausytoją ịvairiais laiko intervalais. Tačiau atspindžių struktūra priklauso nuo to, kokiu impulsu yra sužadinamas garso laukas. Didžiausius atspindžius ganeruoja garsinis pistoletas. Šiu atspindžių amplitudès yra beveik vienodos su tiesioginio garso amplitude per visas $10 \mathrm{~ms}$. Vadinasi, garsinis pistoletas išspinduliuoja daugiau garso energijos negu kiti impulsai. Sužadinant lauką startiniu pistoletu ir medžiokliniu šautuvu, atspindžių struktūra pagal amplitudę labai skiriasi nuo tos, kai sužadinama garsiniu pistoletu. Gerai išskiriamą atspindžių struktūrą suformuoja žaislinis pistoletas, tačiau jo išspinduliuojama energija yra maža.

Garso šaltinis turi būti toks, kad atspindžiu struktūroje būtų matyti atskiri atspindžiai. Nagrinèjant garso šaltinių atspindžių struktūrą, matyti, kad kai kurie atspindžiai sutampa laike. Taip pat matyti, kad, kai impusą generuoja startinis pistoletas ir medžioklinis šautuvas, tai laiko intervale nuo $5 \mathrm{iki} 10 \mathrm{~ms}$ yra daug mažo intensyvumo atspindžių. Tuo tarpu, kai atspindžius generuoja garsinis pistoletas, tai vietoj kelių atspindžiu yra tik vienas, bet jo amplitude yra garokai didesnè. Visa tai atsiliepia rezultatų dažninei analizei. Filtruojant signalą ir ypač nagrinẻjant žemuju dažnių sritị, bütina, kad šiame diapazone enegija būtụ pakankamai didelé tam, kad galima būtų naudingą signalą išskirti iš triukšmo. Šiuo požiūriu geriausi rezultatai gaunami naudojant garsini pistoletą. Tuo tarpu nagrinèjant atspindžių laikines charakteristikas geriausiai tinka garso šaltinis, kurio impulso trukmè yra mažiausia.

Medžioklinis šautuvas generuoja priimtiną atspindžių struktūrą, tačiau jo šūviai yra labai nestabilūs, o tai yra didelis trūkumas atliekant eksperimentą. Tuo tarpu garsinio pistoleto šūviai pagal amplitudę vienas nuo kito skiriasi tik apie $0,1 \%$, t.y. jie yra labai stabi- 
$P$, santykiniai vienetai
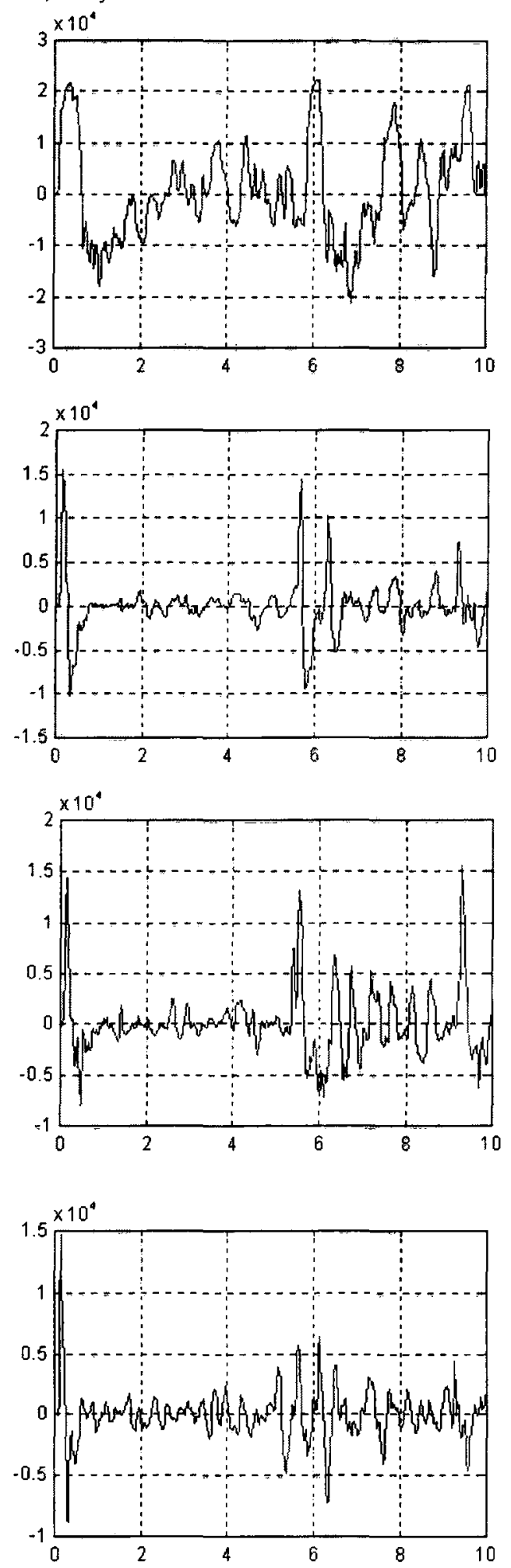

Laikas, ms

1 pav. Garso atspindžių struktūra, gaunama sužadinant garso lauką skirtingais impulsais. Iš viršaus: 9-to kalibro garsinis pistoletas; startinis pistoletas; 16-to kalibro medžioklinis šautuvas; žaislinis pistoletas

Fig 1. Sound reflection structure obtained exciting sound field with diferent pulses. Top - 9-calibre sound pistole; start pistole; 16-calibre hunting gun; toy pistole lūs. Taigi geriausią atspindžių struktūrą iš visų keturių impulsinių šaltinių sukuria garsinis pistoletas.

Didelę itaką matavimų rezultatams turi šaltinio ir mikrofono charakteristikos. Atspindžių amplitudès, be ju laikinio pasiskirstymo, formos ir salès paviršiu apdailos, priklauso ir nuo to, kokiu santykiniu lygiu ir kokia kryptimi buvo išspinduliuojamas impulsas ir koks yra mikrofono jautrumas kryptimi, kuria ateina šis impulsas.

\section{Natūriniụ impulsinių garso šaltinių trukmė ir ju forma}

Kaip buvo minėta, impulsinio garso šaltinio trukmé turi būti nedidelè tam, kad būtų galima gerai atskirti atskirus atspindžius, pasiekiančius klausytoją. Šūvio impulso formą nusako dujų greičio pasiskirstymas išlekiančiose dujose, kurị aprašo Bolcmano pasiskirstymas:

$$
F(v)=4 \pi\left(\frac{m}{2 \pi K_{B} T}\right)^{3 / 2} v^{2} e^{-\frac{m v^{2}}{2 K_{B} T}}
$$

čia $K_{b}$ - Bolcmano pastovioji; $m$ - dujų molekulių masè; $T$ - temperatūra; $V$-dujų molekulių greitis.

Mes registruojame ne greiti, bet susikurianti perteklinį slègi, kuris griežtai susijęs su greičiu. Atlikę analizę gauname, kad

$$
p(t)=A^{-t} e^{-\left(\frac{t}{t_{0}}\right)^{2}}\left(1-\left(\frac{t}{t_{0}}\right)^{2}\right)
$$

čia $A$ yra pastovioji; $t$ - laikas; $t_{0}$ - maksimali impulso trukmè.

2 paveiksle pateikiami 9 kalibro garsinio pistoleto, startinio pistoleto, 16-to kalibro medžioklinio šautuvo ir žaislinio pistoleto sužadinamo impulso formos ir jų trukmès.

Didžiausią impulso trukmè - apie $0,55 \mathrm{~ms}$ yra garsinio pistoleto. Jis ir išspinduliuoja daugiausiai garso energijos. Startinio pistoleto impulso trukmè yra $0,2 \mathrm{~ms}$, medžioklinio šautuvo - $0,18 \mathrm{~ms}$ ir žaislinio pistoleto $-0,15 \mathrm{~ms}$ ir jis yra trumpiausias iš visų keturių impulsų. Pirmujų trijų impulsų formos yra labai panašios ir labai skiriasi nuo garsinio pistoleto impulso formos.

\section{Natūrinio impulsinio garso šaltinio spektras}

Kadangi patalpos atsaką $\mathfrak{i}$ impulsini garso signalą mes registruojame kompiuteriu, t.y. skaitmenine 
Normuotas slègis, santykiniai vienetai

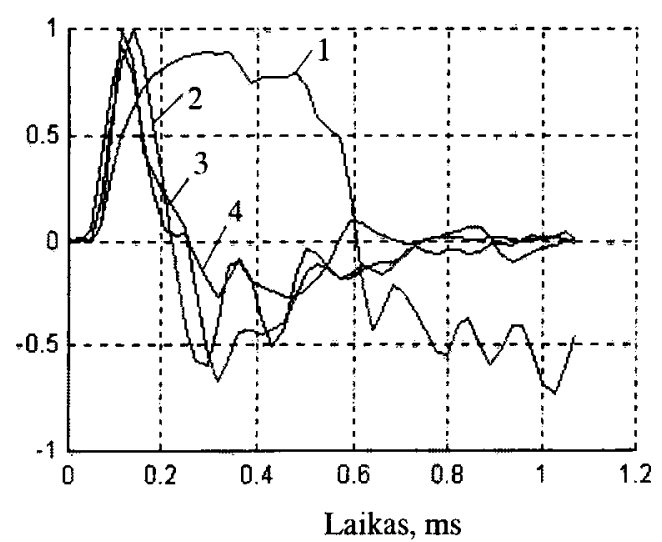

2 pav. İvairių tipų impulsų trukmès ir ju formos. 1 - garsinis pistoletas; 2 - medžioklinis šautuvas; 3 - startinis pistoletas; 4 - žaislinis pistoletas

Fig 2. Duration and forms of different types puises. 1 sound pistole; 2 - hunting gun; 3 - start pistole; 4 - toy pistole

Santykinè energija. $\mathrm{dB}$

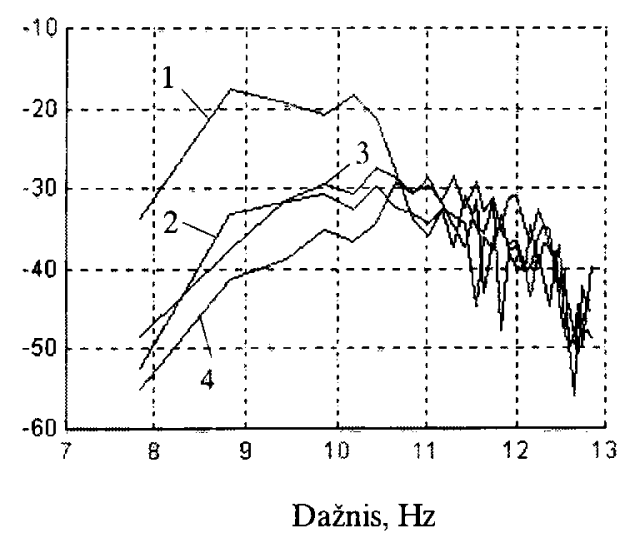

3 pav. İvairaus tipo impulsų spektras. 1 - garsinis pistoletas; 2 - medžioklinis šautuvas; 3 - startinis pistoletas; 4 žaislinis pistoletas

Fig 3. Spectre of pulses of different type. 1 - sound pistole; 2 - hunting gun; 3 - start pistole; 4 - toy pistole

diskretine forma, tai impulsinio garso šaltinio spektras gali būti lengvai nustatomas pagal Furje transformaciją diskretine forma ( 3 pav.).

Grafikas rodo, kad garso šaltinio spektras labai priklauso nuo to, kas sužadina garso lauką. Garsinis pistoletas sukuria spektrą, kurio maksimumo plotis siekia nuo 400 ik $1400 \mathrm{~Hz}$, t.y. užima beveik dvi oktavas. Startinis pistoletas generuoja spektrą nuo 800 iki $2500 \mathrm{~Hz}$. Jis yra gerokai platesnis negu garsinio pistoleto, tačiau jo išspinduliuojama energija yra 10 $\mathrm{dB}$ mažesnè negu garsinio pistoleto. Medžioklinis šautuvas sukuria spektrą nuo $500 \mathrm{iki} 1600 \mathrm{~Hz}$ ir jo energija yra $13 \mathrm{~dB}$ mažesnè negu garsinio pistoleto.
Siauriausią spektrą $(1600-2000 \mathrm{~Hz})$ sukuria žaislinis pistoletas ir jo energija yra $10 \mathrm{~dB}$ mažesnè negu garsinio pistoleto. Šis garso šaltinis sužadina tankiausią atspindžių struktūrą, turinčią mažiausiai energijos. Tai nèra gerai, nes per mažai išspinduliuojama žemuju ir vidutiniu dažnių garso energijos.

Taigi pagal išspinduliuojamą spektro plotị ir energiją geriausias iš keturių garso šaltiniu yra garsinis pistoletas, todè ji galima rekomenduoti tyrimams. Tačiau dar reikia papildomų tyrimų apie tai, kaip priklausomai nuo skirtingu garso šaltinių kinta patalpos objektyvūs ir subjektyvūs akustiniai rodikliai.

\section{Išvados}

1. Saliy akustikos tyrimams galima rekomenduoti 9-to kalibro garsini pistoletą, kuris išspinduliuoja 0,55 ms trukmès impulsą ir kurio spektras beveik lygus 400$1400 \mathrm{~Hz}$.

2. Garsinio pistoleto išspinduliuojama enrgija yra stabili ir ji skiriasi tik apie $0,1 \%$.

3. Startinis pistoletas ir 16-to kalibro medžioklinis šautuvas išspinduliuoja $0,18-0,2$ ms trukmès impulsą, tačiau ju išspinduliuojama energija yra $10-13 \mathrm{~dB}$ mažesnè negu garsinio pistoleto.

4. Medžioklinio šautuvo išspinduliuojama energija yra labai nestabili, o tai yra didelis trūkumas atliekant eksperimentą.

\section{Literatūra}

1. M. Barron. The gulbekian great hall, lisbon, II. An acoustic study of a concert hall with variable stage // Journal of Sound and Vibration, 1978, 59 (4), p. 481502.

2. L. Cremer. Early reflections in some modern concert halls // Journal Acoust. Soc. Amer., 85 (3), March 1989, p. 1213-1225.

3. J. S. Bradley. Acoustical characteristics of guns as impulse sources // Can. Acoust., 13 (2), 1985, p. 16-24.

4. J. S. Bradley. Auditorium acoustics measures from pistol shots // Journal Acoust. Soc. Amer., 80 (1 ), July 1986, p. 199-205.

5. J. S. Bradley. A Comparison of three theaters // Journal Acoust. Soc. Amer., 79 (6), June 1986, p. 1827-1832.

6. J. S. Bradley. A Comparison of three classical concert halls. Journal Acoust. Soc. Amer., 89 (3 ), March 1991, p. 1176-1192.

7. B. Rasmussen, J.H. Rindel and H. Heriksen. Design and Measurement of Short Reverberation Times at Low Frequencies in Talks Studios // Journ. Audio Engineering Society, Vol 39, No 1/2, 1991, January/ February, p. 47-56.

8. Л. Макриненко, Х. Шчиржецкий, М. Селиванов и др. Акустика колонного зала Дома Союзов // Труды НИИСФ, Вып. III, 1982, с. 94-105. 
9. W. Kraak. Elektroakustische Messungen an Raummodelen. Hochfrequenztechnik und Elektroakustic 65, 1956, H. 3, S. 91

10. W. Reichardt, Die Messung raumakusticher Eigenschaften im Modell // Die Schalltechnik 22, 1957, S. 1 I. Polytechn. Tagung der TU Dresden, 1956. Berichtsband S. $231-239$.

11. М. Ю. Ланье. Оптимальный выбор узкополосного импульсного сигнала для исследования ахустических характеристик помещений и их моделей // Труды НИИСФ. Строительная акустика, 1976, т. 15, c. $113-119$

\section{Iteikta 19971220}

\section{ACOUSTIC CHARACTERISTICS OF PULSED SOUND SOURCES OF VARIOUS TYPES}

\section{Stauskis, V. Kunigélis}

\section{Su m m a r y}

The paper examines the acoustic characteristics of explosion-type pulsed sound sources of four types. These include a Calibre 8 sound gun, a start gun, a Calibre 16 hunting gun, and a toy gun. The latter was included both because of its short pulse duration and for comparison purposes. Correct selection of a source is very important because it largely determines the results of acoustic measurements.

Certain requirements are set for a sound source. In order to concentrate as much energy as possible at the given moment, the signal bandwidth-duration product must be as large as possible. The range frequencies to be excited depend on the pulse duration. The latter also determines whether interference phenomena will occur in the room and whether individual reflections will merge.

The experiments were conducted in a room of $12 \mathrm{~m}^{2}$ The distance between the microphone and the pulsed sound source was $1 \mathrm{~m}$.

The structure of reflections depends on the pulse by means of which the sound field is excited. The smallest number of reflections is generated by a sound source. During a $20 \mathrm{~ms}$ experiment, the amplitudes of these reflections almost coincided with the direct sound amplitude. A sound gun emits more sound energy than other pulses. When the sound field is excited by means of a start gun and a hunting gun, the reflection structure, by amplitude, is very different from that produced by a sound gun. A dense reflection structure is formed by a toy gun but it emits less energy.
The structure of reflections generated by a hunting gun is acceptable but its shots are very unstable, which is a major drawback in an experiment. The shots from a sound gun differ only by about $0.1 \%$ among themselves by amplitude, ie they are sufficiently stable. Among the four sound sources, the best reflection structure is produced by a sound gun.

A sound gun is characterised both by the longest pulse duration (about $0.55 \mathrm{~ms}$ ) and the highest levels of energy emitted. The pulse duration of the rest three guns is almost equal and is about $0.15 \mathrm{~ms}$, ie is 3.6 times shorter than that of a sound gun. The forms of signals emitted by these sound sources are also very different.

The spectrum of a sound source was established on Fourier transformation basis. The spectrum is largely dependent on the type of a gun by means of which the sound field is excited. The maximum width of the spectrum generated by a sound gun occupies almost two octaves, from 500 to $2000 \mathrm{~Hz}$, and the radiation in this range is quite uniform. The spectra of a start gun and a hunting gun are similar but these guns emit less sound energy than a sound gun. The structure of reflections generated by them is also quite different. A toy gun radiates energy in a less narrower band, the width of which occupies about a half of octave, with a maximum at $2000 \mathrm{~Hz}$. This is not very good because too small quantities of low- and medium-frequency sound energy are radiated.

Vytautas STAUSKIS. Doctor Habil, Professor. Dept of Building Structures. Vilnius Gediminas Technical University (VGTU), Sauletekio al. 11, LT-2040 Vilnius, Lithuania.

Doctor (1974). From 1974 at VTU Department of Building Structures. Research visits: Moscow Civil Engineering Institute, Sankt-Petersburg Politechnic Institute. Research interests: experimental testing of halls by primary hall models and on site, computer simulation of theoretic tasks, wave diffraction and reflections, direct sound and subjective acoustic indicators, large-dimension resonance structures, early attenuation of acoustic field and its relation to hall acoustics.

Vytautas KUNIGÉLIS. Doctor, Senior scientific researcher. Dept of Radiophysics, Laboratory of physical acoustics. Vilnius University, Sauletekio al. 9, 2040 Vilnius, Lithuania.

A graduate of Vilnius University (1967, radiophysics). Doctor (1972, physics). In 1975 a special course at Higher school of physics and industrial chemistry in France. Research interests: acoustical investigation of solid states and other materials. 